\title{
Social learning about predators: A review and prospectus
}

\author{
A. S. GRIFFIN \\ McGill University, Montreal, Quebec, Canada
}

\begin{abstract}
In comparison with social learning about food, social learning about predators has received little attention. Yet such research is of potential interest to students of animal cognition and conservation biologists. I summarize evidence for social learning about predators by fish, birds, eutherian mammals, and marsupials. I consider the proposal that this phenomenon is a case of S-S classical conditioning and suggest that evolution may have modified some of the properties of learning to accommodate for the requirements of learning socially about danger. I discuss some between-species differences in the properties of socially acquired predator avoidance and suggest that learning may be faster and more robust in species in which alarm behavior reliably predicts high predatory threat. Finally, I highlight how studies of socially acquired predator avoidance can inform the design of prerelease antipredator training programs for endangered species.
\end{abstract}

Intuitively, it seems that antipredator behavior should be fully functional upon a first encounter with danger. Indeed, some stimulus configurations-for example, two black circles - are inherently aversive and trigger avoidance responses in animals with no prior experience of predators (Coss, 1978; Csányi, 1985). On the other hand, there are reasons to predict that under some environmental conditions, antipredator behavior should be ontogenetically flexible. First, predation risk can vary in space and time. Learning allows quantitative levels of antipredator responses to be fine-tuned to local conditions (Lima \& Dill, 1990). Second, environmental change can expose animals to previously unfamiliar predators, and learning allows novel dangers to be recognized (Berger, Swenson, \& Persson, 2001). Third, community structures can change across generations. Under these conditions, recognition of stimuli, such as the alarm behavior of heterospecifics, may not evolve. Learning allows novel cues to become associated with predators. In keeping with these predictions, there is now abundant evidence that learning plays an important role both in the acquisition of antipredator responses and in the adjustment of preexisting ones.

Most known examples of predator avoidance learning involve the use of social information. Unfortunately, the effects of direct experience with predators have received little attention. It is, therefore, difficult to tell whether the apparent importance of social influences on predator avoidance learning reflects an evolutionary trend favor-

The author thanks Louis Lefebvre, Jeff Galef, and Douglas Chivers for comments on this paper. A.S.G. is supported by the Swiss National Foundation for Scientific Research. Correspondence concerning this article should be addressed to A. S. Griffin, Department of Biology, McGill University, 1205 Dr Penfield Ave., Montreal, PQ, H3A 1B1 Canada (e-mail: andrea.griffin @mail.mcgill.ca). ing acquisition of risky information from others, rather than at one's own peril, or an explosion in the amount of research on social learning in the last 2 decades. Two patterns of social influence on predator avoidance have emerged. First, exposure to the alarm behavior of predatorexperienced social companions can enhance the frequency (Palleroni, 1999) or the specificity (Cheney \& Seyfarth, 1990) of antipredator responses of juveniles or can cause response specificity to develop more quickly (Mateo, 1996; Mateo \& Holmes, 1997). The second pattern of learning involves the acquisition of responses to previously unfamiliar stimuli and occurs in both juveniles and adults. This process has been termed observational conditioning (Cook, Mineka, Wolkenstein, \& Laitsch, 1985), or releaser-induced recognition learning (Suboski, 1990), and is the focus of the present review.

Socially acquired predator avoidance is a taxonomically widespread phenomenon that has been found in fish, birds, eutherians, and marsupials. The pattern of acquisition is similar across groups. Before learning, subjects show little or no response to a given stimulus. After that stimulus has been presented together with an alarm signal, however, it evokes an avoidance response.

Several authors have noted the similarity between the process of predator avoidance acquisition and Pavlovian S-S conditioning (Heyes, 1994; Mineka \& Cook, 1993; Shettleworth, 1998; Suboski, 1990). Within this framework, the predatory cue is considered a conditional stimulus (CS) to which observers acquire avoidance responses after the stimulus has been presented in contiguity with an alarmed demonstrator, the unconditioned stimulus (US). Such an analysis is supported by the positive correlations between levels of demonstrator and observer alarm behavior during training and by the positive correlations between observer fear levels during and after training (Mineka \& Cook, 1993). Socially acquired predator 
avoidance has recently been demonstrated in tammar wallabies (Macropus eugenii), an Australian macropodid marsupial (Griffin \& Evans, 2003). This finding extended the existence of such learning to a new taxonomic group and provided the impetus for the present review.

My objectives here are both to provide an overview of past work and to suggest new research approaches to mechanisms of socially transmitted predator avoidance. First, I will summarize the evidence for socially transmitted predator avoidance in fish, birds, and eutherian and marsupial mammals. I chose this taxonomic focus because the vast majority of studies on socially acquired predator avoidance have been conducted in these groups, even though such learning might occur in other taxa, such as amphibians and reptiles (Suboski, 1992). Second, I will examine whether the properties of learning support the idea that socially acquired predator avoidance is mediated by asocial learning mechanisms, rather than by some independent social learning process. Third, I will highlight some species differences and discuss possible reasons for them. Finally, I will briefly illustrate how the findings from basic studies of socially acquired predator avoidance can inform the design of prerelease antipredator training programs for endangered species.

\section{FISH}

Predator avoidance learning in fish has been the focus of much basic research. There is some evidence that direct experience with predators (being startled or chased) can inculcate antipredator responses or enhance preexisting ones (Järvi \& Uglem, 1993). However, social cues seem to be particularly effective for triggering predator avoidance learning in this group.

\section{Social Stimuli That Trigger Learning in Observers}

The most intensively studied associative paradigm in fish has involved paired presentations of unfamiliar predator cues with alarm pheromones. Von Frisch (1938) discovered that the skin of an injured fish releases chemical substances that evoke alarm responses in receivers. Shortly thereafter, Göz (1941) showed that these substances facilitate predator avoidance learning. Göz found that blinded European minnows (Phoxinus phoxinus) displayed an alarm response to a predator odor to which they had previously been indifferent after experiencing that odor in the presence of injured conspecifics. Decades later, the effects of alarm substances were isolated by extracting them from the skin of donor fish, and it was shown that chemical substances alone are sufficient to trigger learning (Magurran, 1989; Suboski et al., 1990). Today, the role of injury-released chemical cues in socially acquired predator avoidance has been demonstrated in a range of species, including several outside the superorder Ostariophysi, to which such learning was originally thought to be restricted (for reviews, see C. Brown \& Laland, 2001; Chivers \& Smith, 1998). More recently, a second category of chemical alarm substances, referred to as disturbance cues, has also been identified (for a review, see Chivers \& Smith, 1998). These chemicals are released when a fish detects a predator. Although prior exposure to these substances and unfamiliar predators appears to enhance survival in staged predatory encounters (Mirza \& Chivers, 2002), it is not known whether disturbance cues facilitate predator recognition learning, as do damage-released alarm cues.

Conspecific alarm substances that trigger avoidance responses in fish with no prior experience of them (Göz, 1941; Magurran, 1999; Suboski et al., 1990) may function as USs during training (Suboski, 1990). The association of a chemical US and a predatory CS resembles the association of carbon disulfide and a food odor that mediates learning about novel foods in rats (Galef, 1996). In contrast to chemically induced food preferences, however, visual stimuli produced by alarmed conspecifics can also facilitate predator recognition. Naive individuals observing fearful demonstrators through a clear barrier while simultaneously experiencing novel predator cues acquire antipredator responses to these predator cues (Chivers \& Smith, 1994a; Suboski et al., 1990). In the case of visual cues, it is more difficult to specify the nature of the US producing predator avoidance. Specific movement patterns of the demonstrator, such as dashing (Chivers \& Smith, 1994a), or position relative to the substrate might be important, but there have been no attempts to investigate the role of such features in learning. The recent development of movement analysis algorithms allows dynamic stimuli to be encoded quantitatively (Peters, Clifford, \& Evans, 2002), and video-editing computer software can be used to build dynamic video stimuli and to manipulate movement cues while controlling for morphology. Test stimuli are then presented to observers on high-resolution monitors, a technique known to evoke biologically meaningful responses in several species of fish (see, e.g., Kodric-Brown \& Nicoletto, 2001; Trainor \& Basolo, 2000). Such an approach could, hence, be used to understand which aspects of a fearful demonstrator trigger learning in their observers.

Social transmission of predator avoidance is not restricted to conspecifics. Both chemical alarm substances and the sight of alarmed shoalmates in mixed species aggregations facilitate antipredator learning in heterospecifics. For example, the alarm pheromones (Chivers, Brown, \& Smith, 1995) or the sight (Mathis, Chivers, \& Smith, 1996) of fathead minnows (Pimephales promelas) mediate acquired antipredator responses in brook stickleback (Culaea inconstans). Unlike responses to conspecific alarm substances, which appear to be experience independent (Magurran, 1999), there is evidence that responses to heterospecific alarm substances are learned (Chivers, Mirza, \& Johnston, 2002; Chivers \& Smith, 1994b). In fathead minnows, responses to heterospecific alarm substances are acquired socially through associations with conspecific alarm substances (Mirza $\&$ Chivers, 2001). Social learning thus allows both for 
novel predators to be recognized and for novel cues to become associated with predators.

\section{Content of Learning}

Fish can acquire fear responses to a range of stimuli, including biologically meaningful olfactory and visual cues, such as the odor (Chivers \& Smith, 1994c; Magurran, 1989) or sight (Chivers \& Smith, 1994a) of predators. Fish can also learn to avoid specific habitats after these have become associated with the presence of chemical alarm substances (Chivers \& Smith, 1995a). A range of arbitrary olfactory and visual cues, such as morpholine (Suboski et al., 1990) or red lights (D. Hall \& Suboski, 1995; Yunker, Wein, \& Wisenden, 1999), can also acquire control over fear responses, once they have been reliably associated with predation risk. To my knowledge, only one study has shown that acquired responses are specifically evoked by the training stimulus (Chivers \& Smith, 1994a). Fathead minnows trained to respond fearfully to predatory pike respond to pike but do not display a fear response to goldfish. Similarly, minnows that have been conditioned to respond fearfully to goldfish do not generalize their acquired response to pike.

\section{Properties of Learning}

Preferential learning. Despite the apparent flexibility in the kind of information that can be acquired, there is some evidence that socially acquired predator avoidance is adaptively biased. Magurran (1989) found that European minnows can be conditioned to respond to odors of both nonpredatory tilapia (Tilapia mariae) and predatory pike but that the magnitude of the acquired response to the predator is higher than that to the nonpredator. Attempts to determine which stimulus features are more readily associated with fear have shown that motion, but not shape, triggers preferential learning (Wisenden \& Harter, 2001).

Evidence for a slightly different kind of constraint comes from work on fathead minnows. Predator-naive individuals acquire fear responses to the sight of predatory northern pike (Esox lucius) that are similar to those acquired to nonpredatory goldfish (Carassius auratus), but 2 months after conditioning, learned responses to pike are greater than responses to goldfish (Chivers \& Smith, 1994a).

Behavior of observer during training, speed of acquisition, duration of acquired responses, latent inhibition, and context specificity. Studies of socially acquired predator avoidance in fish have shown consistently that both chemical and visual cues evoke alarm responses in observers during training (Chivers \& Smith, 1994a; Suboski et al., 1990). Predator recognition is typically acquired in a single paired presentation of social and novel stimuli and is retained for up to 2 months (Chivers \& Smith, 1994a). Effects of prior habituation to the CS on acquisition have not been investigated in this taxonomic group. Acquired antipredator responses are not context specific. Groups of fathead minnows pre- and posttested in the laboratory but trained in the field show significant acquired responses to a novel predator (G. E. Brown, Chivers, \& Smith, 1997; Chivers \& Smith, 1995b).

Transmission across chains of individuals and through populations. The transmission of socially acquired predator avoidance across chains of individuals has been documented in several species of fish (D. Hall \& Suboski, 1995; Suboski et al., 1990). Initial demonstrators are conditioned using paired presentations of predator cues and chemical alarm substances, whereas subsequent groups can be trained by mixing naive individuals with experienced demonstrators and presenting predator cues (Suboski et al., 1990). Under laboratory conditions, transmission occurs across at least three groups of naive observers (Suboski et al., 1990). Alarm responses to risky habitats can also be transmitted to naive shoal mates from individuals trained with chemical alarm substances (Chivers \& Smith, 1995a).

In addition to chain transmission experiments in the laboratory, there has been one attempt to quantify the spread of acquired predator avoidance through a natural population. Predator awareness spreads rapidly through a predator-naive population after introduction of a predatory species (Chivers \& Smith, 1995b). Ten predatory pike were released into a predator-free population of approximately 20,000 fathead minnows. Laboratory measures showed that each pike consumed from 2 to 5 minnows per day. Fathead minnows showed no alarm responses to pike odor before the introduction. Tested only 14 days later, the minnows displayed high-level responses to pike odor. Field studies have the obvious disadvantage that mechanisms of transmission cannot be specified. In particular, the effects of individual learning cannot be separated from the effects of social learning. Nevertheless, the rapidity with which predator awareness spread in this study suggests that learning did not rely solely on individual exposure to the predators.

Functional benefits of socially acquired predator avoidance. The functional benefits of socially acquired predator avoidance have been examined in several species by comparing survival of trained and nontrained fish during staged encounters with predators (Berejikian, Smith, Tezak, Schroder, \& Knudsen, 1999; Chivers et al., 2002; Järvi \& Uglem, 1993; Mirza \& Chivers, 2000). Trained fish had consistently higher survival rates than did untrained fish in both laboratory and field studies.

\section{BIRDS}

Predator avoidance learning has received less attention in birds than in fish. Most recent work has been motivated by efforts to enhance survival rates of endangered avian species bred in captivity and released into the wild (Maloney \& McLean, 1995; McLean, Hölzer, \& Strudholme, 1999; van Heezik, Seddon, \& Maloney, 1999). For conservation purposes, experiments are not designed to enhance the understanding of mechanisms of acquisition 
but, rather, to maximize the likelihood of learning. Consequently, training regimes usually engage both individual and social acquisition processes. As in fish, basic research has revealed evidence for individuallearning about predators (Kramer \& von St. Paul, 1951) but has focused primarily on elucidating the mechanisms of socially acquired predator avoidance (Curio, 1988, 1993; Curio, Ernst, \& Vieth, 1978). After anecdotal observations by Lorenz $(1952,1969)$ in corvids and preliminary tests of socially transmitted avoidance of feeding dishes in ducks (Klopfer, 1957), Kruuk (1976) was the first to investigate whether predator avoidance could be socially transmitted in birds. However, Curio et al. (1978) provided the first compelling demonstration of socially acquired predator avoidance. Since then, a handful of other studies have demonstrated socially acquired predator avoidance in other species, including starlings (Sturnus vulgaris; Conover \& Perito, 1981), ring-billed gulls (Larus delawarensis; Conover, 1987), and New Zealand robins (Petroica australis; Maloney \& McLean, 1995; McLean et al., 1999). Curio's work remains, however, the most detailed study of socially acquired predator avoidance in avians.

\section{Social Stimuli That Trigger Learning in Observers}

Mobbing is a compound social stimulus that incorporates both visual (tail and wing flicks and predatordirected dives) and acoustic (alarm calls) signals in response to predators. The results from several studies suggest that mobbing acts as a US that triggers learning in observers (Conover, 1987; Curio et al., 1978; Kruuk, 1976; Maloney \& McLean, 1995; McLean et al., 1999). For example, Kruuk found that, relative to control birds, both lesser black-backed (Larus fuscus) and herring (Larus argentatus) gulls alight at a significantly greater distance from a model stoat after they have seen the model stoat holding a dead gull and have participated in mobbing aggregations around the predator. Unfortunately, Kruuk's experimental situation made it impossible to separate the role of mobbing conspecifics from that of the dead bird itself in acquired predator avoidance. Curio et al. subsequently demonstrated that European blackbirds (Turdus merula) learn to mob a species of bird to which they are initially indifferent (Australian honeyeater, Philemon corniculatus), once they have seen a conspecific appear to mob it.

Both visual and acoustic cues alone suffice to trigger predator avoidance learning. Conover and Perito (1981) found that significantly fewer starlings alighted at food placed close to a model owl (Bubo virginianus) after they had seen the predator holding a struggling starling in its talons and that latencies to land were significantly longer. During training, the live conspecific was tethered to the predator model but did not vocalize, suggesting that visual alarm cues alone facilitated predator avoidance learning. Kruuk's (1976) work on free-living sea gulls also suggests that observers may become more cau- tious after having seen a predator holding a dead conspecific. Acoustic playbacks of conspecific alarm calls are known to trigger predator avoidance learning in observers (Vieth, Curio, \& Ernst, 1980).

Just as chemical alarm substances emitted by one fish species can trigger predator avoidance learning in another species, heterospecific alarm calls can initiate cross-species learning. Paired presentations of an unfamiliar model bird and a multispecies alarm chorus inculcate antipredator responses in blackbirds that are similar to those of birds trained with a conspecific demonstrator (Vieth et al., 1980). Responses to heterospecific alarm calls might be acquired, perhaps through direct associations with predators (Shriner, 1999) or, as in fish (Mirza \& Chivers, 2001) and primates (Hauser, 1988), secondary associations with conspecific alarm calls. However, there have been no direct tests of this hypothesis.

\section{Content of Learning}

Both basic and applied research programs have shown consistently that birds acquire fear responses to model vertebrates, both predatory and nonpredatory, and that such acquired responses are specific to the training stimulus. For example, Kruuk (1976) found that sea gulls alighted at a greater distance from a model stoat after training but found no changes in behavior toward a hedgehog, suggesting that the acquired wariness was specific to the predator. Similarly, birds trained to respond to model vertebrates do not respond to arbitrary control stimuli after training (empty box, Curio et al., 1978; plastic bottle, McLean et al., 1999).

\section{Properties of Learning}

Preferential learning. There is evidence for preferential learning in birds. The initial presentation of a model Australian honeyeater (Philemon corniculatus) evokes a greater response from blackbirds than does a plastic bottle, and when each of these stimuli is paired with the experience of a conspecific appearing to mob them, the magnitude of the acquired antipredator response to the honeyeater is much greater (Curio et al., 1978).

Behavior of observer during training, speed of acquisition, duration of acquired responses, latent inhibition, and context specificity. As in fish, observer alarm levels reflect those of the demonstrators during training (Curio et al., 1978). Predator recognition is acquired after one paired presentation of the social and the novel stimuli and has been shown to be retained for at least 8 days (Curio et al., 1978). Blackbirds acquire fear responses to a CS even if they have received repeated presentations of the stimulus before social conditioning (Curio et al., 1978). The context specificity of acquired responses has not been tested in avians.

Transmission across chains and functional benefits of learning. Curio et al. (1978) tested transmission across a chain of 6 blackbirds and found no decline in acquired responses. However, the acquired responses of 
the observers were higher during posttraining tests than during their subsequent service as demonstrators, suggesting that acquired responses are less robust in blackbirds than in the fish species tested to date.

Only one applied study has addressed the question of whether socially acquired predator avoidance enhances the likelihood of survival. Survival rates of houbara bustards (Chlamydotis undulata) conditioned to respond to a live predator were higher than those of untrained birds (van Heezik, Seddon, \& Maloney, 1999). Conditioning engaged, however, both individual (being chased by a predator) and social (presence of predator-experienced demonstrator) learning processes.

\section{EUTHERIAN MAMMALS}

Findings from field experiments with mammals strongly suggest that social learning plays a role in acquired predator avoidance. Free-living mother moose (Alces alces) behave more cautiously in response to wolf (Canis lupus) howls once they have lost an offspring to this predator (Berger et al., 2001). It is possible, however, that experience with wolves involves both social (observing a predatory event on a social companion) and individual (being chased) experience. Field studies do not allow identification of the mechanism of transmission. However, field studies are very important because they indicate the biological significance of phenomena observed in the laboratory. Socially acquired object avoidance has been demonstrated under controlled conditions in several eutherian mammals, including rats (Rattus norvegicus; Lore, Blanc, \& Suedfeld, 1971), pata monkeys (Erythrocebus patas; K. R. L. Hall, 1968), squirrel monkeys (Saimiri sciureus; Herzog \& Hopf, 1984; Huebner, Lentz, Wooley, \& King, 1979), and rhesus monkeys (Macaca mulatta; Mineka \& Cook, 1988). But the most compelling evidence for socially acquired predator avoidance in eutherian mammals is that provided by Mineka, Cook, and their colleagues in studies of rhesus monkeys (for a review, see Mineka \& Cook, 1988), the only eutherian system in which mechanisms of social learning of predator avoidance have been explored systematically.

\section{Social Stimuli That Trigger Learning in Observers}

Mineka, Cook, and colleagues demonstrated in a series of papers that juvenile rhesus monkeys fear snakes after watching a social companion respond fearfully to a snake. Like the mobbing behavior of birds, alarm responses of rhesus monkeys are compound signals containing both acoustic (e.g., vocalizations and teeth chattering) and visual (e.g., piloerection and specific body postures) components, both of which appear to function as USs (Mineka \& Cook, 1993). There is also evidence that an acoustic alarm signal on its own is sufficient to trigger predator avoidance learning. Two juvenile squirrel monkeys became more fearful of a model predator once it had been presented in conjunction with experimental playbacks of conspecific terrestrial alarm yaps (Herzog \& Hopf, 1984).

\section{Content of Learning}

Alarm behavior can be conditioned to both model and live predators (Herzog \& Hopf, 1984; Mineka \& Cook, 1988), and acquired responses are relatively specific to the conditioned stimulus. After training, rhesus monkeys conditioned to respond fearfully to snakes did not generalize their acquired response to control stimuli, such as wood blocks and electrical cords (Mineka \& Cook, 1988). Similarly, a squirrel monkey, conditioned to avoid a model cat paired with conspecific alarm calls, did not respond fearfully to a model snake that, during training, had been presented simultaneously with a control sound (Herzog \& Hopf, 1984).

\section{Properties of Learning}

Preferential learning. In monkeys, as in birds, antipredator responses are associated with some stimuli preferentially. For example, rhesus monkeys failed to acquire fear responses to a toy rabbit or flowers even after watching video sequences of conspecifics behaving fearfully toward these stimuli (Cook \& Mineka, 1989, 1990). Interestingly, second-order avoidance conditioning does not seem to be subject to such constraints. Monkeys conditioned to respond fearfully to snakes later acquire fear responses to an arbitrary object (striped box, a secondorder CS) when it was reliably associated with presentation of a snake (a first-order CS; Cook \& Mineka, 1990).

Behavior of the observer during training, speed of acquisition, duration of acquired responses, latent inhibition, and context specificity. As in other taxonomic groups, the alarm behavior of observer rhesus monkeys correlates positively with that of demonstrators during training (Mineka \& Cook, 1993). Observer fear responses reach asymptotic levels after only one conditioning trial and are maintained over the course of five subsequent training sessions. However, responses learned in two training trials are retained for at least 3 months, longer than those learned in one training trial (Mineka \& Cook, 1993). As in birds, there is evidence that latent inhibition does not impair learning. Monkeys exposed to six presentations of a snake and food before fear conditioning nevertheless acquire fear responses to the snake after watching a demonstrator respond fearfully to it (Mineka \& Cook, 1986). Finally, by conditioning rhesus monkeys in one context and testing them in another, Mineka, Davidson, Cook, and Keir (1984) demonstrated that acquired fear responses are not context specific.

Transmission across chains and through populations. Cook et al. (1985) demonstrated that individuals that have acquired fear responses to snakes after watching wild-reared demonstrators respond fearfully to them can be used as demonstrators for yet another group of naive observers. However, fear responses tended to decline in laboratory-conditioned individuals over the course of their use as demonstrators, and acquired responses in ob- 
servers were somewhat lower than they were after the first round of conditioning (Cook et al., 1985). Transmission across longer chains has not been tested.

\section{MARSUPIAL MAMMALS}

Marsupial species were traditionally incorporated into studies of learning so that the performance of eutherian mammals could be compared with that of a group presumed to be evolutionarily less "complex" (for a review, see Wynne \& McLean, 1999). Phylogenetic analyses have now revealed that marsupial mammals diverged from placental mammals about 100 million years ago and represent a parallel evolutionary lineage (Springer, Westerman, \& Kirsch, 1994). Consequently, the supposition that marsupials might be in some way "inferior" to eutherians is no longer justified.

Australian kangaroos and wallabies (Macropodidae) display clear antipredator responses that involve both visual (erect body postures and fleeing) and acoustic (alarm foot thumping) cues. Griffin and Evans (2003) investigated the potential of such stimuli to trigger predator avoidance learning in tammar wallabies, a medium sized (4-7 kg), moderately social kangaroo. First, they enhanced the responses of individual wallabies to a taxidermically prepared model predator (fox, Vulpes vulpes) by presenting it in conjunction with a simulated capture by a human. After training, the wallabies responded to the fox with high levels of alarm behavior, including fleeing and alarm foot thumping. Repeated presentations of the model fox alone were used to habituate another group to the predator. After training, the wallabies in this group responded to the fox by briefly orienting toward it. Both groups of wallabies (fox fearful and fox indifferent) were then used as demonstrators to test whether acquired responses could be socially transmitted. Naive observers given the opportunity to watch trained demonstrators respond fearfully to the fox watched the predator significantly more after training than did control observers that had watched an indifferent demonstrator respond to the predator stimulus.

Attempts to test whether acoustic alarm stimuli alone are sufficient to trigger learning have yielded variable results. McLean, Lundie-Jenkins, and Jarman (1996) showed that rufous hare wallabies (Lagorchestes hirsutus) watch a model fox more after they have experienced it in conjunction with playbacks of conspecific alarm thumps. However, similar experiments with tammar wallabies found no effect of this acoustic signal on learning, but this may have been due to the small number of subjects in the study (Griffin, 2003).

\section{Content of Learning}

To determine whether socially acquired responses were specific to the predator with which wallabies were trained, Griff in and Evans (2003) measured responses to an array of stimuli both before and after training. They found that the acquired response was specific to the training model (fox) and to another morphologically similar predator (cat, Felis catus), although the learned response to the cat was transient. Wallabies did not behave differently in response to a model nonpredator (goat, Capra hircus) after training with a fox model.

\section{Properties of Learning}

Preferential learning. There have been no attempts to determine whether socially acquired predator avoidance in marsupials is biased toward some kinds of stimuli. It is known, however, that individually trained tammar wallabies preferentially associate predators with fear (Griffin, Evans, \& Blumstein, 2002). Possibly, social learning about predators will show a similar bias.

Behavior of the observer during training, speed of acquisition, duration of acquired responses, latent inhibition, and context specificity. As in other species, the vigilance levels of observer wallabies correlated positively with those of their demonstrators during training (Griffin \& Evans, 2003). Observer responses reached maximum levels after two training trials, suggesting that social learning about predators is as rapid in marsupials as in all the other species tested to date. However, in wallabies, unlike in rhesus monkeys (Mineka \& Cook, 1988), the responses of observers declined over the course of two subsequent training trials, despite the fact that demonstrators continued to respond fearfully to the predator. The duration and context specificity of acquired responses, as well as the effects of latent inhibition, have not been investigated in marsupials.

\section{GENERAL CONCLUSIONS ON SOCIALLY ACQUIRED PREDATOR AVOIDANCE}

The properties of socially acquired predator avoidance are remarkably similar across groups (Table 1). The intensity of observer alarm responses increases with the intensity of demonstrator responses during training, acquisition occurs in one to two trials, and there is preferential learning about particular kinds of stimuli. These properties provide support for the idea that socially acquired predator avoidance is mediated by individual learning processes and not by any independent social learning mechanism (Heyes, 1994; Mineka \& Cook, 1993; Suboski et al., 1990). First, traditional studies of classical conditioning have shown that the intensity of an unconditioned response (UR) usually increases with that of the US. The positive relationship between observer and demonstrator alarm thus supports the idea that social alarm cues function as USs that evoke URs in observers. Second, it is known that stimuli associated with arbitrary aversive events, such as an electric shock, can be acquired significantly in one trial and reach asymptotic levels after very few CS-US pairings (Young \& Fanselow, 1992). Rapid acquisition is, therefore, not particular to socially acquired predator avoidance but, rather, to fear conditioning in general. Third, selective associations are present not only in socially acquired fear, but also in individually condi- 
Table 1

Summary of the Principal Properties of Socially Acquired Predator Avoidance

\begin{tabular}{|c|c|c|c|c|}
\hline Property & Fish & Birds & Eutherians & Marsupials \\
\hline $\begin{array}{l}\text { Social cues that trigger } \\
\text { learning in observers }\end{array}$ & $\begin{array}{l}\text { Chemical alarm substances } \\
\text { Visual alarm cues }\end{array}$ & $\begin{array}{l}\text { Compound visual and } \\
\text { acoustic alarm cues } \\
\quad \text { (mobbing) } \\
\text { Visual cues } \\
\text { Alarm vocalizations }\end{array}$ & $\begin{array}{l}\text { Compound visual and } \\
\text { acoustic alarm cues } \\
\text { Alarm vocalizations }\end{array}$ & $\begin{array}{l}\text { Compound visual and } \\
\text { acoustic alarm cues } \\
\text { Acoustic alarm thumps }\end{array}$ \\
\hline Cross-species learning & Yes & Yes & Not known & Not known \\
\hline Speed of learning & One CS-US presentation & One CS-US presentation & Two CS-US presentations & Two CS-US presentations \\
\hline Content of learning & $\begin{array}{l}\text { Olfactory predator and } \\
\text { arbitrary stimuli } \\
\text { Visual predator and } \\
\text { arbitrary stimuli } \\
\text { Habitats }\end{array}$ & $\begin{array}{l}\text { Visual predator and } \\
\text { nonpredator stimuli }\end{array}$ & Visual predator stimuli & Visual predator stimuli \\
\hline Specificity of learning & $\begin{array}{l}\text { No generalization to } \\
\text { nonpredator fish }\end{array}$ & $\begin{array}{l}\text { No generalization to } \\
\text { inanimate object }\end{array}$ & $\begin{array}{l}\text { No generalization to } \\
\text { inanimate object or } \\
\text { to morphologically } \\
\text { different predator }\end{array}$ & $\begin{array}{l}\text { No generalization to } \\
\text { nonpredator }\end{array}$ \\
\hline Duration of learning & 2 months & 8 days & 30 days & Not known \\
\hline Preferential learning & Yes & Yes & Yes & Not known \\
\hline Effect of latent inhibition & Not known & None & None & Not known \\
\hline $\begin{array}{l}\text { Context specificity of } \\
\text { acquired responses }\end{array}$ & None & Not known & None & Not known \\
\hline $\begin{array}{l}\text { Observer-demonstrator } \\
\text { alarm behavior during } \\
\text { training }\end{array}$ & Positive relationship & Positive relationship & Positive relationship & Positive relationship \\
\hline
\end{tabular}

tioned fear. Rats learn to recognize a tone more readily than a light as a signal for an electric shock. In recent years, general models of learning have been adjusted to incorporate parameters accounting for stimulus associability. Consequently, preferential associations are not considered to reflect any specialized learning process.

Only one property points to a difference between classical fear conditioning and socially acquired predator avoidance. In both blackbirds and rhesus monkeys, prior habituation to the CS does not seem to affect subsequent acquisition of a fear response to that stimulus (Curio et al., 1978; Mineka \& Cook, 1986). In contrast, CSs that signal the absence of a frightening US in classical aversive conditioning do not subsequently acquire control over conditioned fear (Young \& Fanselow, 1992). The idea that socially acquired avoidance might not be affected by phenomena known to influence the likelihood of classical conditioning is consistent with the results of other studies of social learning (Galef \& Durlach, 1993). Tests of the effect of CS-US presentation order might reveal another difference between individually and socially acquired fear. It is known that backward conditioning, in which the US is presented before the CS, does not always lead to conditioned fear responses (e.g., Kalish, 1967; but see Arcediano \& Miller, 2002). One might predict that this order of presentation should have no effect on socially acquired predator avoidance, because it emulates a natural situation in which an individual first observes an alarmed conspecific and then identifies the source of alarm. Future studies are needed to test whether evolution has modified other properties of classical con- ditioning to accommodate for the requirements of learning socially about danger.

Despite an overall similarity, there are some species differences in the properties of socially acquired predator avoidance (Table 1). In fish, one presentation of a predatory CS together with a chemical alarm US appears to induce robust antipredator behavior. Propagation occurs along chains of individuals with no apparent decline in either demonstrator alarm or learned responses (Suboski et al., 1990). In contrast, in rhesus monkeys, one training trial induces fear responses that are less robust than those induced by two training trials. In addition, even though responses acquired in two trials are retained longer, they are not resistant to extinction. Fear acquired by observers tends to decrease when these individuals are used as demonstrators for another set of naive observers (Cook et al., 1985). In blackbirds, the situation is somewhat intermediate. Although one-trial learning appears to lead to robust responses that can be transmitted along chains with no apparent decline, subjects show lower responses during their use as demonstrators than immediately after training (Curio et al., 1978). It is not known whether socially acquired fear responses are resistant to extinction in tammar wallabies, because there have been no chain transmission experiments with wallabies. There is some evidence, however, that observer responses tend to reach maximum levels after two training trials and to decrease over the course of further training sessions (Griffin \& Evans, 2003). Together, these results suggest that the social acquisition of fear in fish is rapid and robust. Other species may require more numerous, more varied, and/or 
more temporally spaced out learning opportunities for acquisition to be robust. Interactions between social and individual learning might also consolidate information acquired socially, as has been shown for socially acquired food preferences (Galef \& Whiskin, 2001).

Functional considerations might help explain why learning may be more robust in some species than in others. Intuitively, it seems that predator avoidance learning should be extremely rapid and, once acquired, should always be retained. On the other hand, one might predict that learning should be fast and lead to permanent changes in behavior only if social alarm cues are reliably associated with danger and threat is very high. As risk decreases, opportunity for repeated learning trials increases, particularly in social learning that does not entail a direct risk to the observer. In fish, damage-released chemical alarm cues are emitted by injured individuals, so such USs should be reliable predictors of the presence of a predator and should reflect high levels of risk. Consequently, in fish, selection may have favored learning that was fast and resistant to habituation. An equivalent social experience for a mammal or a bird might be observing another individual being killed. Behaviors associated with alarm in birds and monkeys are not always associated with the presence of a predator. For example, territorial birds mob conspecific intruders. Consequently, it might not be advantageous to learn immediately and irreversibly to fear an event associated with mobbing.

\section{SOCIALLY ACQUIRED PREDATOR AVOIDANCE AND WILDLIFE CONSERVATION}

Understanding whether, how, and under which conditions animals learn socially about predators is of potential interest to those involved in conservation programs for endangered wildlife. Reintroduction of animals bred in captivity has become a common conservation strategy, but few programs have succeeded in establishing sustainable populations (Wolf, Griffith, Reed, \& Temple, 1996). Predation is a common cause of failure of reintroductions (e.g., Dunham, 1997). Consequently, prerelease predator avoidance training has been used to improve antipredator skills. Training usually involves simultaneous presentation of a target predator and an unpleasant event (reviewed by Griffin, Blumstein, \& Evans, 2000). Research into the underpinnings of socially acquired predator avoidance can inform the design of prerelease antipredator training techniques. In addition, changes in behavior that are obtained by engaging natural predator avoidance learning mechanisms are more likely to make a difference to postrelease survival (Griff in et al., 2000).

The interaction between basic and applied research in this field is particularly well illustrated in fish. Large numbers of hatchery-reared juveniles are released each year to supplement natural populations available to the fishing industry (C. Brown \& Laland, 2001). The mor- tality rates of hatchery-reared young are considerably higher than those of wild-reared individuals (Maynard, Flagg, \& Mahnken, 1995), and predation is the principal cause of death (Howell, 1994). Antipredator training has the potential to make hatchery-reared fish more predator aware and, hence, to improve their survival. The design of antipredator training techniques has benefited hugely from the procedures and findings from basic work on predator recognition learning (C. Brown \& Laland, 2001). In particular, the findings that (1) socially acquired predator avoidance is widespread, (2) social training can lead to recognition of target predators, (3) acquired predator awareness can propagate through a population, and (4) learning enhances the likelihood of survival have encouraged development of antipredator training programs. There is an urgent need to further the basic study of socially acquired predator avoidance in birds and mammals so that similar progress can be made.

\section{REFERENCES}

Arcediano, F., \& Miller, R. R. (2002). Some constraints for models of timing: A temporal coding hypothesis perspective. Learning \& Motivation, 33, 105-123.

Berejikian, B. A., Smith, R. J. F., TeZak, E. P., Schroder, S. L., \& Knudsen, C. M. (1999). Chemical alarm signals and complex hatchery rearing habitats affect antipredator behavior and survival of chinook salmon (Oncorhynchus tshawytscha) juveniles. Canadian Journal of Fisheries \& Aquatic Sciences, 56, 830-838.

Berger, J., Swenson, J. E., \& Persson, I.-L. (2001). Recolonizing carnivores and naive prey: Conservation lessons from Pleistocene extinctions. Science, 291, 1036-1039.

BRown, C., \& LALAND, K. (2001). Social learning and life skills training for hatchery reared fish. Journal of Fish Biology, 59, 471-493.

Brown, G. E., Chivers, D. P., \& SMith, R. J. F. (1997). Differential learning rates of chemical versus visual cues of a northern pike by fathead minnows in a natural habitat. Environmental Biology of Fishes, 49, 89-96.

Cheney, D. L., \& SEyfarth, R. M. (1990). How monkeys see the world. Chicago: University of Chicago Press.

Chivers, D. P., Brown, G. E., \& Smith, R. J. F. (1995). Acquired recognition of chemical stimuli from pike, Esox lucius, by brook sticklebacks, Culaea inconstans (Osteichthyes, Gasterosteidae). Ethology, 99, 234-242.

Chivers, D. P., Mirza, R. S., \& Johnston, J. G. (2002). Learned recognition of heterospecific alarm cues enhances survival during encounters with predators. Behaviour, 139, 929-938.

Chivers, D. P., \& SMith, R. J. F. (1994a). Fathead minnows, Pimephales promelas, acquire predator recognition when alarm substance is associated with the sight of unfamiliar fish. Animal Behaviour, 48, 597-605.

Chivers, D. P., \& SMith, R. J. F. (1994b). Intra- and interspecific avoidance of areas marked with skin extract from brook sticklebacks ( $\mathrm{Cu}$ laea inconstans) in a natural habitat. Journal of Chemical Ecology, 20, 1517-1524.

Chivers, D. P., \& SMith, R. J. F. (1994c). The role of experience and chemical alarm signalling in predator recognition by fathead minnows, Pimephales promelas. Journal of Fish Biology, 44, 273-285.

Chivers, D. P., \& SMith, R. J. F. (1995a). Chemical recognition of risky habitats is culturally transmitted among fathead minnows, Pimephales promelas (Osteichthyes, Cyprinidae). Ethology, 99, 286-296.

Chivers, D. P., \& SMITH, R. J. F. (1995b). Free-living fathead minnows rapidly learn to recognize pike as predators. Journal of Fish Biology, 46, 949-954.

Chivers, D. P., \& Smith, R. J. F. (1998). Chemical alarm signalling in aquatic predator-prey systems: A review and prospectus. Écoscience, 5, 338-352. 
Conover, M. R. (1987). Acquisition of predator information by active and passive mobbers in ring-billed gull colonies. Behaviour, 102, 4157.

Conover, M. R., \& Perito, J. J. (1981). Response of starlings to distress calls and predator models holding conspecific prey. Zeitschrift für Tierpsychologie, 57, 163-172.

COOK, M., \& MinEKA, S. (1989). Observational conditioning of fear to fear-relevant versus fear-irrelevant stimuli in rhesus monkeys. Journal of Abnormal Psychology, 98, 448-459.

COOK, M., \& MinEKA, S. (1990). Selective associations in the observational conditioning of fear in rhesus monkeys. Journal of Experimental Psychology: Animal Behavior Processes, 16, 372-389.

Cook, M., Mineka, S., Wolkenstein, B., \& Laitsch, K. (1985). Observational conditioning of snake fear in unrelated rhesus monkeys. Journal of Abnormal Psychology, 94, 591-610.

Coss, R. G. (1978). Perceptual determinants of gaze aversion by the lesser mouse lemur (Microcebus murinus): The role of two facing eyes. Behaviour, 64, 248-270.

CSÁNYI, V. (1985). Ethological analysis of predator avoidance by the paradise fish (Macropodus opercularis L.): I. Recognition and learning of predators. Behaviour, 92, 227-240.

CURIO, E. (1988). Cultural transmission of enemy recognition by birds In T. R. Zentall \& B. G. Galef, Jr. (Eds.), Social learning: Psychological and biologicalperspectives (pp. 75-97). Hillsdale, NJ: Erlbaum.

CURIO, E. (1993). Proximate and developmental aspects of antipredator behavior. Advances in the Study of Behavior, 22, 135-238.

CURIO, E., ERnST, U., \& VIETH, W. (1978). The adaptive significance of avian mobbing: II. Cultural transmission of enemy recognition in blackbirds: Effectiveness and some constraints. Zeitschrift für Tierpsychologie, 48, 184-202.

DUNHAM, K. M. (1997). Population growth of mountain gazelles Gazella gazella reintroduced to Central Arabia. Biological Conservation, 81, 205-214.

GALEF, B. G., JR. (1996). Social enhancement of food preferences in Norway rats: A brief review. In C. M. Heyes \& B. G. Galef, Jr. (Eds.) Social learning in animals: The roots of culture (pp. 49-64). New York: Academic Press.

GAlEF, B. G., JR., \& DURLACH, P. J. (1993). Absence of blocking, overshadowing, and latent inhibition in social enhancement of food preferences. Animal Learning \& Behavior, 21, 214-220.

GALEF, B. G., JR., \& WHISKIN, E. E. (2001). Interaction between social and individual learning in food preferences of Norway rats. Animal Behaviour, 62, 41-46.

Göz, H. (1941). Über den Art- und Individualgeruch bei Fischen Zeitschrift für vergleichende Physiologie, 29, 1-45.

GRIFFIN, A. S. (2003). Training tammar wallabies to respond to predators: Linking experimental psychology to conservation. International Journal of Comparative Psychology, 16, 111-129.

Griffin, A. S., Blumstein, D. T., \& Evans, C. S. (2000). Training captive-bred or translocated animals to avoid predators. Conservation Biology, 14, 1317-1326.

GRIFFIN, A. S., \& EvANS, C. S. (2003). Social learning of antipredator behaviour in a marsupial. Animal Behaviour, 66, 485-492.

Griffin, A. S., Evans, C. S., \& Blumstein, D. T. (2002). Selective learning in a marsupial. Ethology, 108, 1103-1114.

Hall, D., \& Suboski, M. D. (1995). Visual and olfactory stimuli in learned release of alarm reactions by zebra danio fish (Brachydanio rerio). Neurobiology of Learning \& Memory, 63, 229-240.

HaLl, K. R. L. (1968). Social learning in monkeys. In P. C. Jay (Ed.), Primates: Studies in adaptation and variability (pp. 383-397). New York: Holt, Rinehart \& Winston.

HAUSER, M. D. (1988). How infant vervet monkeys learn to recognize starling alarm calls: The role of experience. Behaviour, 105, 187-201.

Herzog, M., \& HoPf, S. (1984). Behavioral responses to species-specific warning calls in infant squirrel monkeys reared in social isolation. American Journal of Primatology, 7, 99-106.

HEYES, C. M. (1994). Social learning in animals: Categories and mechanisms. Biological Review, 69, 207-231.

Howe LL, B. R. (1994). Fitness of hatchery-reared fish for survival in the sea. Aquaculture \& Fisheries Management, 25(Suppl. 1), 3-17.

Huebner, D. K., LentZ, J. L., WoOley, M. J., \& King, J. E. (1979). Re- sponses to snakes by surrogate- and mother-reared squirrel monkeys. Bulletin of the Psychonomic Society, 14, 33-36.

JÄRVI, T., \& UGLEM, I. (1993). Predator training improves the antipredator behaviour of hatchery reared Atlantic salmon (Salmo salar) smolt. Nordic Journal of Freshwater Research, 68, 63-71.

KALISH, H. I. (1967). Strength of fear as a function of the number of acquisition and extinction trials. In R. M. Elliott, G. Lindzey, \& K. MacCorquodale (Eds.), Foundations of conditioning and learning (pp. 428-439). New York: Appleton-Century-Crofts.

KLOPFE R, P. H. (1957). An experiment of empathic learning in ducks. American Naturalist, 41, 61-63.

Kodric-Brown, A., \& Nicoletto, P. F. (2001). Female choice in the guppy (Poecilia reticulata): The interaction between male color and display. Behavioral Ecology \& Sociobiology, 50, 346-351.

KrAmer, G., \& VON ST. PAUl, U. (1951). Über angeborenes und erworbenes Feinderkennen beim Gimpel (Pyrrhula pyrrhula L.). Behaviour, 3, 243-255.

KRUUK, H. (1976). The biological function of gulls' attraction towards predators. Animal Behaviour, 24, 146-153.

LimA, S. L., \& DiLl, L. M. (1990). Behavioral decisions made under the risk of predation: A review and prospectus. Canadian Journal of Zoology, 68, 619-640.

Lore, R., Blanc, A., \& Suedfeld, P. (1971). Empathic learning of a passive-avoidance response in domesticated Rattus norvegicus. Animal Behaviour, 19, 112-114.

LoREnZ, K. Z. (1952). King Solomon's ring. New light on animal ways. New York: Crowell.

LoREnZ, K. Z. (1969). Innate bases of learning. In K. H. Pribram (Ed.), On the biology of learning (pp. 13-93). New York: Harcourt, Brace \& World.

MAGURRAN, A. E. (1989). Acquired recognition of predator odour in the European minnow (Phoxinus phoxinus). Ethology, 82, 216-223.

MAgurRan, A. E. (1999). The causes and consequences of geographic variation in antipredator behavior: Perspectives from fish populations. In S. A. Foster \& J. A. Endler (Eds.), Geographic variation in behavior: Perspectives on evolutionary mechanisms (pp. 139-163). Oxford: Oxford University Press.

Maloney, R. F., \& MCLeAn, I. G. (1995). Historical and experimental learned predator recognition in free-living New Zealand robins. Animal Behaviour, 50, 1193-1201.

MATEO, J. M. (1996). The development of alarm-call response behaviour in free-living juvenile Belding's ground squirrels. Animal Behaviour, 52, 489-505.

Mateo, J. M., \& Holmes, W. G. (1997). Development of alarm-call responses in Belding's ground squirrels: The role of dams. Animal Behaviour, 54, 509-524.

Mathis, A., Chivers, D. P., \& Smith, R. J. F. (1996). Cultural transmission of predator recognition in fishes: Intraspecific and interspecific learning. Animal Behaviour, 51, 185-201.

MaYnard, D. J., FlagG, T. A., \& Mahnken, C. V. W. (1995). A review of seminatural culture strategies for enhancing the postrelease survival of anadromous salmonid. In H. L. Schramm, Jr., \& R. G. Piper (Eds.), American Fisheries Society Symposium 15 (pp. 307-314). Bethesda, MD.

Mclean, I. G., Hölzer, C., \& Strudholme, B. J. S. (1999). Teaching predator-recognition to a naive bird: Implications for management. Biological Conservation, 87, 123-130.

MCLeAn, I. G., Lundie-Jenkins, G., \& JARMAn, P. J. (1996). Teaching an endangered mammal to recognise predators. Biological Conservation, 75, 51-62.

MiNEKA, S., \& COOK, M. (1986). Immunization against the observational conditioning of snake fear in rhesus monkeys. Journal of $A b$ normal Psychology, 95, 307-318.

MineKA, S., \& COOK, M. (1988). Social learning and the acquisition of snake fear in monkeys. In T. R. Zentall \& B. G. Galef, Jr. (Eds.), Social learning: Psychological and biologicalperspectives (pp. 51-73). Hillsdale, NJ: Erlbaum.

MineKA, S., \& CoOK, M. (1993). Mechanisms involved in the observational conditioning of fear. Journal of Experimental Psychology: General, 122, 23-38.

MineKa, S., DAvidson, M., Cook, M., \& KeIR, R. (1984). Observa- 
tional conditioning of snake fear in rhesus monkeys. Journal of $A b$ normal Psychology, 93, 355-372.

MirZA, R. S., \& ChIVERS, D. P. (2000). Predator-recognition training enhances survival of brook trout: Evidence from laboratory and fieldenclosure studies. Canadian Journal of Zoology, 78, 2198-2208.

MIRZA, R. S., \& CHIVERS, D. P. (2001). Learned recognition of heterospecific alarm signals: The importance of a mixed predator diet. Ethology, 107, 1007-1018.

MiRzA, R. S., \& Chivers, D. P. (2002). Behavioural responses to conspecific disturbance chemicals enhance survival of juvenile brook charr, Salvelinus fontinalis, during encounters with predators. Behaviour, 139, 1099-1109.

PALLERONI, A. R. (1999). Anti-predator behavior of galliform birds. Unpublished doctoral dissertation, University of California, Davis.

Peters, R. A., Clifford, C. W. G., \& Evans, C. S. (2002). Measuring the structure of dynamic visual signals. Animal Behaviour, 64, 131-146.

SHETtLeWORTH, S. J. (1998). Cognition, evolution, and behavior. New York: Oxford University Press.

SHRINER, W. M. (1999). Antipredator responses to a previously neutral sound by free-living adult golden-mantled ground squirrels, Spermophilus lateralis (Sciuridae). Ethology, 105, 747-757.

SPRINGER, M. S., WeSterman, M., \& KIrSCH, J. A. W. (1994). Relationships among orders and families of marsupials based on $12 \mathrm{~S} \mathrm{ri-}$ bosomal DNA sequences and the timing of the marsupial radiation. Journal of Mammalian Evolution, 2, 85-115.

Suboski, M. D. (1990). Releaser-induced recognition learning. Psychological Review, 97, 271-284.

Suboski, M. D. (1992). Releaser-induced recognition learning by amphibians and reptiles. Animal Learning \& Behavior, 20, 63-82.

Suboski, M. D., Bain, S., CARTY, A. E., MCQuoid, L. M., Seelen, M. I., \& SEIFERT, M. (1990). Alarm reaction in acquisition and social trans- mission of simulated-predator recognition by zebra danio fish (Brachydanio rerio). Journal of Comparative Psychology, 104, 101112.

Trainor, B. C., \& BASOLO, A. L. (2000). An evaluation of video playback using Xiphophorus helleri. Animal Behaviour, 59, 83-89.

van HeE ZIK, Y., Seddon, P. J., \& MaloneY, R. F. (1999). Helping reintroduced houbara bustards avoid predation: Effective anti-predator training and the predictive value of pre-release behaviour. Animal Conservation, 2, 155-163.

VIETH, W., Curio, E., \& ERnst, U. (1980). The adaptive significance of avian mobbing: III. Cultural transmission of enemy recognition in blackbirds: Cross-species tutoring and properties of learning. Animal Behaviour, 28, 1217-1229.

VON FRISCH, K. (1938). Zur Psychologie des Fische-Schwarmes. Naturwissenschaften, 26, 601-606.

WisENDEN, B. D., \& HARTER, K. R. (2001). Motion, not shape, facilitates association of predation risk with novel objects by fathead minnows (Pimephales promelas). Ethology, 107, 357-364.

Wolf, C. M., Griffith, B., Reed, C., \& Temple, S. A. (1996). Avian and mammalian translocations: Update and reanalysis of 1987 survey data. Conservation Biology, 10, 1142-1154.

WynNe, C. D. L., \& MCLean, I. G. (1999). The comparative psychology of marsupials. Australian Journal of Psychology, 51, 1-6.

YounG, S. L., \& FANSELOW, M. S. (1992). Associative regulation of Pavlovian fear conditioning: Unconditional stimulus intensity, incentive shifts, and latent inhibition. Journal of Experimental Psychology: Animal Behavior Processes, 18, 400-413.

YunKeR, W. K., Wein, D. E., \& Wisenden, B. D. (1999). Conditioned alarm behavior in fathead minnows (Pimephales promelas) resulting from association of chemical alarm pheromone with a nonbiological visual stimulus. Journal of Chemical Ecology, 25, 2677-2686. 